Gut 1986, 27, 186-189

Liver and biliary

\title{
Ethanol metabolism in the generation of new antigenic determinants on liver cells
}

\author{
I R CROSSLEY, J NEUBERGER, M DAVIS, ROGER WILliAMS, AND \\ A L W F EDDLESTON \\ From the Liver Unit, King's College School of Medicine and Dentistry, Denmark Hill, London
}

SUMMARY Antibodies directed against ethanol altered liver cell components have been detected in the serum of nearly $50 \%$ of patients with alcoholic liver disease although the pathogenetic mechanisms are unclear. The importance of ethanol metabolism in the generation of new antigenic determinants on liver cells was investigated by in vivo inhibition of alcohol or acetaldehyde dehydrogenase and an induced cytotoxicity assay. There was a significant reduction in cytotoxicity to hepatocytes isolated from rabbits treated with ethanol $1 \mathrm{~g} / \mathrm{kg}$ when the metabolism of ethanol to acetaldehyde by alcohol dehydrogenase was inhibited. In contrast when the oxidation of acetaldehyde was inhibited by disulfiram cytotoxicity was significantly enhanced. These results show that ethanol metabolism is integral to the expression of the ethanol related determinant and suggest that an impaired ability to metabolism acetaldehyde could lead to the development of immunological reactions to alcohol altered liver membrane antigens.

Although the risk of developing alcoholic cirrhosis is related to the quantity and duration of alcohol consumption $^{1}$ and good evidence exists for a direct toxic effect of ethanol or one of its metabolites on hepatocyte function ${ }^{2}$ there is considerable variation in the individual susceptibility to the hepatotoxic effects of alcohol. ${ }^{3}$ The association between the histocompatability antigens HLA B8 and DR3, genetic markers of several immune mediated disorders, and the more rapid development of cirrhosis ${ }^{4}$ in addition to the increased incidence of autoantibodies in patients with alcoholic cirrhosis suggest the involvement of host immune factors. ${ }^{5}$

In patients with alcoholic hepatitis, several investigations have shown cellular immune reactions to normal rabbit hepatocytes, ${ }^{6}$ acetaldehyde ${ }^{7}$ and alcoholic hyaline. ${ }^{8}$ Antibodies reacting with normal liver cell components such as the liver specific lipoprotein complex have also been identified in the sera of patients with alcoholic hepatitis and cirrhosis. ${ }^{9}$ Most recently immunofluorescence studies and induced cytotoxicity assays have shown that nearly $50 \%$ of patients with alcoholic liver damage have a circulating antibody which reacts with alcohol specific determinants present on the surface of hepatocytes isolated from ethanol treated rabbits. ${ }^{10} 11$ The speci-

Address for correspondence: Dr Roger Williams FRCP, Liver Unit, King's College School of Medicine and Dentistry, Denmark Hill, London SE5 8RX. Received for publication 28 May 1985 fic involvement of an antibody/antigen interaction in the cytoxocity reactions was demonstrated by blocking studies using $F(a b)_{2}$ fragment of the antibody to the Fc portion of human immunoglobulin, thereby preventing the binding of effector lymphocytes to, and lysing, antibody tested target cells. The percentage cytotoxicity with this technique fell from $42 \pm 10 \%$ to $9.2 \pm 9 \%(\mathrm{p}<0.01)$. That antibody was reacting with a surface determinant was shown by absorption studies where sera inducing significant cytotoxicity were incubated with alcohol altered hepatocytes to remove antibodies reacting with alcohol altered liver cell determinants. After absorption none of the sera induced significant cytotoxicity. Alcohol specific antibodies were not found in the sera of normal individuals or in patients with other forms of acute or chronic liver disease. The nature and mechanism of generation of such new antigenic determinants is unclear but could arise either as a direct effect of ethanol on the hepatocyte membrane or as a result of an interaction between one of its metabolites such as acetaldehyde with cellular macromolecules. Variations in the rate of ethanol metabolism and subsequent generation and removal of toxic intermediary metabolites which are largely under genetic control ${ }^{12}$ might be of importance in this respect.

Alcohol dehydrogenase is quantitatively the most important enzyme capable of catalysing the conversion of ethanol to acetaldehyde whilst the latter is 
oxidised to acetate by aldehyde dehydrogenase. In this study we have investigated the importance of ethanol metabolism and acetaldehyde disposal in the generation of new antigenic determinants by in vivo inhibition of the enzymes alcohol and aldehyde dehydrogenase.

\section{Methods}

\section{MATERIALS}

\section{PREPARATION OF ETHANOL ALTERED} HEPATOCYTES

The ethanol altered antigen is generated in vivo in rabbits given ethanol $(1 \mathrm{~g} / \mathrm{kg} / \mathrm{day})$ by intraperitoneal injection for seven days. In preliminary studies animals were given ethanol $0.5 \mathrm{~g} / \mathrm{kg}$ or $0.1 \mathrm{~g} / \mathrm{kg}$ daily by intraperitoneal injection to determine a threshold dose which alone did not generate the antigen. Subsequently, this low dose of ethanol or $1 \mathrm{~g} / \mathrm{kg}$ was administered together with inhibitors of the enzymes alcohol dehydrogenase (4 methyl pyrazole) and aldehyde dehydrogenase (disulfiram) to inhibit or enhance generation of the relevant antigen in vivo.

Female New Zealand white rabbits were used throughout the study. Groups of animals were given either ethanol $1 \mathrm{~g} / \mathrm{kg}$ and 4 methyl pyrazole $0 \cdot 2$ $\mathrm{mmol} / \mathrm{kg}$, ethanol $0 \cdot 1 \mathrm{~g} / \mathrm{kg}$ and 4 methyl pyrazole 0.2 $\mathrm{mmol} / \mathrm{kg}$, ethanol $0.1 \mathrm{~g} / \mathrm{kg}$ and disulfiram $100 \mathrm{mg} / \mathrm{kg}$ or disulfiram $100 \mathrm{mg} / \mathrm{kg}$ alone, daily for seven days. Disulfiram was administered orally for three days before and during treatment with ethanol. 4 Methyl pyrazole and ethanol were given by simultaneous intraperitoneal injection. On the eighth day the animals were killed by injection with $300 \mathrm{mg}$ pentabarbitone and 100 IU preservative free heparin. The livers were removed under sterile procedure and flushed with the culture medium RPMI 1640 with glutamine (Gibco) containing penicillin $150 \mathrm{mg} / \mathrm{l}$, streptomycin $150 \mathrm{mg} / \mathrm{l}$ and amphotericin $0.4 \mathrm{mg} / \mathrm{l}$.

\section{CYTOTOXIC ASSAY}

The presence of the altered hepatocyte antigen was detected using 10 sera known to contain the specific antibody from a previous induced cytotoxic assay. ${ }^{10}$ In the presence of the altered antigen the antibody will bind to the cell and render it susceptible to cytotoxicity by normal lymphocytes in the cytotoxic assay.

The liver was minced using sterile scalpels and, after three washings was incubated for four hours with $0.01 \%$ collagenase (Boehringer) in $10 \%$ fetal calf serum (Gibco) and RPMI 1640 at $37^{\circ} \mathrm{C}$ in an atmosphere of $5 \% \mathrm{CO}_{2} / 95 \% \mathrm{O}_{2}$. After serial washings isolated hepatocytes were removed and maintained in short term tissue culture for up to one week. Hepatocytes were then seeded into micro cytotoxicity plates (Falcon) to give 200 cells per well. After overnight incubation at $37^{\circ} \mathrm{C}$, the cells were incubated for two hours with $10 \mu \mathrm{l}$ of test serum absorbed with normal hepatocytes and diluted 1 in 100 in RPMI 1640 or $10 \%$ fetal calf serum in at least 10 separate test wells.

Lymphocytes were isolated from normal individuals using dextran sedimentation, cotton wool incubation and Ficoll-Triosil density centrifugation. Lymphocytes were then added to the washed hepatocytes to give a ratio of 100 lymphocytes to each hepatocyte. After fixing and staining the remaining adherent hepatocytes were counted without knowledge of the dose of ethanol or enzyme inhibitor used and the percentage cytotoxicity determined from the formula:

$$
\% \text { cytoxicity }=\frac{\mathrm{NC}-\mathrm{NT}}{\mathrm{NC}} \times 100
$$

where $\mathrm{NC}=$ mean number of cells remaining in control wells and NT $=$ mean number of cells remaining in test wells.

\section{Results}

All 10 sera induced significant cytotoxicity (median $41 \%$, range $37-53 \%$ ) to hepatocytes isolated from rabbits pretreated with ethanol $1 \mathrm{~g} / \mathrm{kg}$ daily ('high dose'), whilst only one of these sera induced significant cytotoxicity to target hepatocytes isolated from rabbits pretreated with ethanol $0 \cdot 1 \mathrm{~g} / \mathrm{kg}$ ('low dose'). The median cytotoxicity value of $8 \%$ (range $0-53 \%$ ) for the latter group was significantly different to values in the high dose ethanol treated group $(p<0.01)$ (Fig. 1). None of the sera induced cytotoxicity against hepatocytes from a control, non-alcohol treated group of animals (Fig. 2).

There was a significant reduction in induced cytotoxicity to hepatocytes isolated from animals pretreated with high dose ethanol when the metabolism of ethanol to acetaldehyde by alcohol dehydrogenase was inhibited with 4 methyl pyrazole (median cytotoxicity $22 \%$, range $0-55 \% \mathrm{p}<0.01$ ) (Fig. 2).

Furthermore, when the oxidation of acetaldehyde was inhibited by disulfiram in animals treated with low dose ethanol all 10 sera demonstrated enhanced cytotoxicity to target hepatocytes. The median cytotoxicity value of $37 \%$ (range $34-45 \%$ ) was significantly different from that obtained with low dose ethanol treatment alone $(p<0 \cdot 01)$.

There was no enhanced cytotoxicity against hepatocytes isolated from animals treated only with 


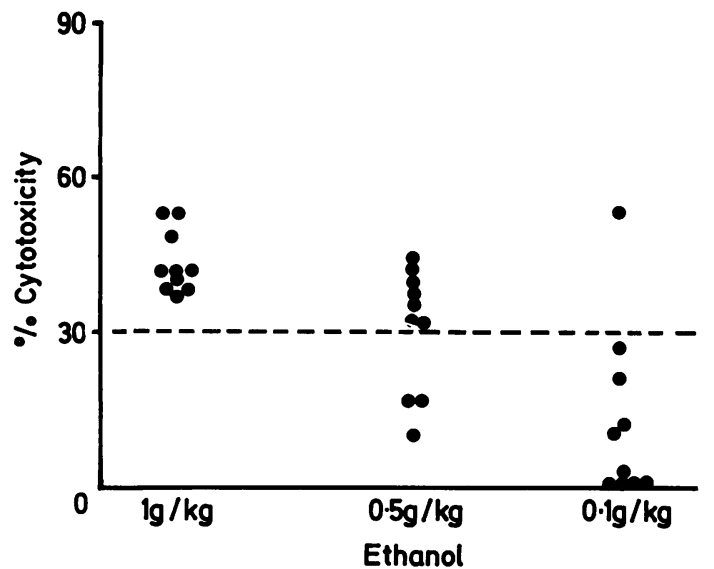

Fig. 1 Percentage cytotoxicity of 10 sera known to contain the alcohol antibody against hepatocytes isolated from rabbits pretreated with different doses of ethanol $-1 \mathrm{~g} / \mathrm{kg}$, $0.5 \mathrm{~g} / \mathrm{kg}, 0.1 \mathrm{~g} / \mathrm{kg}$ body weight. Dotted line represents the upper limit of normal.

disulfiram. No variation in the cytotoxicity induced by control sera to target hepatocytes was observed with either disulfiram or 4 methyl pyrazole.

\section{Discussion}

Administration of ethanol has been shown to alter the structure of hepatocyte plasma membrane preparations with attendant changes in membrane fluidity ${ }^{13}$ which could expose antigenic determinants which are not normally accessible to circulating components of the immune system.

The present findings of a significant reduction in cytotoxicity when the oxidation of ethanol to acetaldehyde by alcohol dehydrogenase was inhibited by 4 methyl pyrazole, suggest, however, that such a direct effect is improbable and that ethanol metabolism is a prerequisite for the expression of new antigenic determinants on liver cells. Furthermore, the observation that cytotoxicity to target hepatocytes isolated from rabbits pretreated with low dose ethanol alone is significantly enhanced when the metabolism of acetaldehyde is inhibited with disulfiram suggest that acetaldehyde is specifically responsible for initiating changes in the hepatocyte plasma membrane. Supportive evidence that an aldehyde radical plays a crucial role in generation of altered liver cell determinants after alcohol administration is reported by MacSween. ${ }^{14}$ Hepatocytes isolated from rabbits pretreated with either methanol, ethanol or propran-1-ol, all of which are metabolised to their corresponding aldehydes within the liver resulted in significantly enhanced liver membrane antibody seropositivity which was not evident with pretreatment with propran-2-ol which is metabolised to the corresponding ketone.

The precise mechanism whereby acetaldehyde

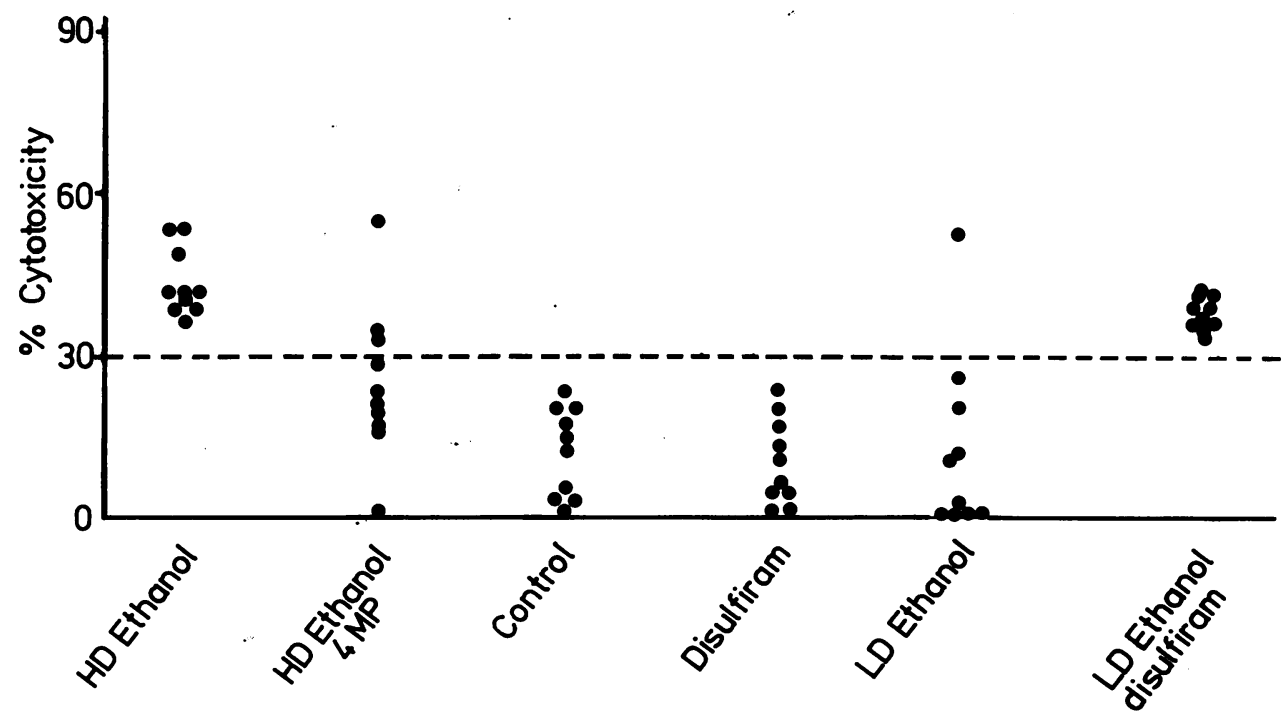

Fig. 2 Percentage cytotoxicity of 10 sera known to contain alcohol antibody against hepatocytes isolated from control rabbits and those treated with 'high' dose ethanol ( $\mathrm{HD}$ ethanol, $1 \mathrm{~g} / \mathrm{kg}$ ), high dose ethanol and 4 methyl pyrazole, disulfiram alone, 'low'dose ethanol ( $L D$ ethanol, $0 \cdot 1 \mathrm{~g} / \mathrm{kg}$ ) or low dose ethanol and disulfiram. Dotted line represents the upper limit of normal. 
might induce a change in liver cell membrane reactivity remains to be determined. A direct immunogenic role for acetaldehyde is unlikely because of its small molecular size. Nevertheless, it is a highly reactive molecule which has been shown to bind to cellular macromolecules. ${ }^{15}$ Current concepts of plasma membrane biogenesis suggest that a chemically reactive metabolite binding to the smooth endoplasmic recitulum could become translocated to the cell surface and become incorporated as a hapten into the plasma membrane. ${ }^{16}$

Our earlier finding of a circulating antibody in patients with alcoholic liver damage which reacts with an alcohol specific antigen present on the surface of rabbit hepatocytes suggests that a similar if not identical altered membrane antigen is generated in man by chronic alcohol consumption. Acetaldehyde has long been incriminated in the pathogenesis of alcoholic liver damage and recent evidence suggests that it binds to hepatocyte plasma membranes. ${ }^{17}$ The absence of any associated change in membrane function or cell metabolism at concentrations likely to be found in vivo, however, suggest that any injurious effect is most probably mediated by the immune system after a change in membrane structure. It remains to be established whether immune reactions directed against acetaldehyde related liver cell membrane determinants are implicated in the pathogenesis of alcoholic liver disease. Using currently available techniques the antibody can be detected in only half of these patients..$^{10} 11$ The expression of the new antigenic determinant is likely to be influenced by the inherent variations in the rate of acetaldehyde metabolism in addition to the recently recognised reduction in acetaldehyde dehydrogenase activity consequent upon chronic ethanol consumption. ${ }^{18} 19$

Hence, if mechanisms similar to those observed in this study also occur in man, an impaired ability to metabolise acetaldehyde would lead to the generation of new liver membrane antigens, immune recognition of which could lead to enhanced liver cell destruction.

Preliminary results were presented at the 18th meeting of the European Association for the Study of the Liver, 1983. Dr J Neuberger is Wellcome Senior Clinical Research Fellow. The support of the Department of Health and Social Security and the Brewers' Society are gratefully acknowledged.

\section{References}

1 Rubin E, Leiber CS, Ethanol metabolism in liver disease. In: Popper H, Schaffner F, eds. Progress in liver disease. New York: Grune and Stratton, 1972:
$549-66$.

2 Rubin E, Cederbaum AI. Organelle pathology of alcohol-induced hepatic injury. In: Fisher MM, Rankin JG eds. Alcohol and the liver. New York and London: Plenum Press, 1977: 167-93.

3 Galambos JT. Alcoholic hepatitis. In: Schaffner F, Sherlock S, Leevy CM, eds. The liver and its diseases. New York: Intercontinental Medical Book, 1974: 225-67.

4 Saunders JB, Wodak AD, Haines A et al. Accelerated development of alcoholic cirrhosis in patients with HLA B8. Lancet 1982; 1: 1381-4.

5 Bailey RJ, Krasner N, Eddleston ALWF et al. Histocompatibility antigens, autoantibodies and immunoglobulins in alcoholic liver disease. $\mathrm{Br}$ Med J 1976; 2: 727-31.

6 Cochrane AMG, Moussouros A, Thomson AD, Portmann B, Eddleston ALWF, Williams R. Lymphocyte cytotoxicity to isolated hepatocytes in alcoholic liver disease. Gastroenterology 1977; 72: 918-23.

7 Actis GC, Ponzetto A, Rizzetto M, Verme G. Cell mediated immunity to acetaldehyde in alcoholic liver disease demonstrated by the leucocyte migration test. Am J Dig Dis 1978; 23: 883-6.

8 Zetterman RK, Luisade-Opper A, Leevy CM. Alcoholic hepatitis. Cell mediated immune response to alcoholic hyaline. Gastroenterology 1976; 70: 382-4.

9 Perperas A, Tsantoulas D, Portmann B, Eddleston ALWF, Williams R. Autoimmunity to a liver membrane lipoprotein and liver damage in alcoholic liver disease. Gut 1981; 22: 149-53.

10 Neuberger J, Crossley IR, Saunders JB et al. Antibodies to alcohol altered liver cell determinants in patients with alcoholic liver disease. Gut 1984; 25: $300-4$.

11 MacSween RNM, Anthony RS, Farquharson M. Antibodies to alcohol-altered hepatocytes in patients with alcoholic liver disease. Lancet 1981; 2: 803-4.

12 Vesel ES, Page JG, Passananti ST. Genetic and environmental factors affecting ethanol metabolism in man. Clin Pharmacol Ther 1971; 12: 192-201.

13 Freund G. Possible relationships of alcohol in membrane to cancer. Cancer Res 1979; 39: 2899-901.

14 Anthony RS, Farquharson M, MacSween RNM. Liver membrane antibodies in alcoholic liver disease II. Antibodies to ethanol altered hepatocytes. J Clin Pathol 1983; 36: 1302-8.

15 Donohue TM, Tuma DJ, Sorrell M. Binding of metabolically derived Acetaldehyde to hepatic proteins in vitro. Lab Invest 1983; 49: 226-9.

16 Morre DJ, Kartenbeck J, Franke WW. Membrane flow and interconversions among endomembranes. Biochim Biophys Acta 1979; 559: 71-152.

17 Barry RE, McGiven JD, Hayes M Read AE. Acetaldehyde is not directly hepatotoxic in alcoholic liver disease. Clin Sci 1983; 65: 230.

18 Palmer KR, Jenkins WJ. Impaired acetaldehyde oxidation in alcoholics. Gut 1982; 23: 729-33.

19 Jenkins WJ, Cakebread K, Palmer KR. Effects of alcohol consumption on hepatic aldehyde dehydrogenase activity in alcoholic patients. Lancet 1984; 1: 1048-9. 